
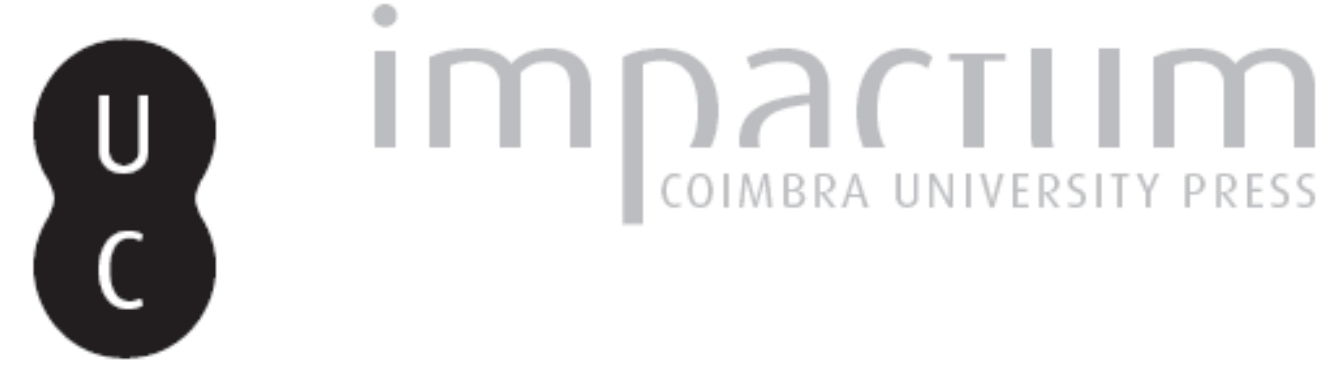

\title{
[Recensão a] PAIVA, José Pedro - Baluartes da Fé e da Disciplina. $O$ enlace entre a Inquisição e os bispos em Portugal (1536-1750)
}

\author{
Autor(es): $\quad$ Rosa, Carla
}

Publicado por: Centro de História da Sociedade e da Cultura

URL

persistente:

URI:http://hdl.handle.net/10316.2/39495

DOI:

DOI:http://dx.doi.org/10.14195/1645-2259_11_21

Accessed : $\quad$ 26-Apr-2023 14:01:45

A navegação consulta e descarregamento dos títulos inseridos nas Bibliotecas Digitais UC Digitalis, UC Pombalina e UC Impactum, pressupõem a aceitação plena e sem reservas dos Termos e Condições de Uso destas Bibliotecas Digitais, disponíveis em https://digitalis.uc.pt/pt-pt/termos.

Conforme exposto nos referidos Termos e Condições de Uso, o descarregamento de títulos de acesso restrito requer uma licença válida de autorização devendo o utilizador aceder ao(s) documento(s) a partir de um endereço de IP da instituição detentora da supramencionada licença.

Ao utilizador é apenas permitido o descarregamento para uso pessoal, pelo que o emprego do(s) título(s) descarregado(s) para outro fim, designadamente comercial, carece de autorização do respetivo autor ou editor da obra.

Na medida em que todas as obras da UC Digitalis se encontram protegidas pelo Código do Direito de Autor e Direitos Conexos e demais legislação aplicável, toda a cópia, parcial ou total, deste documento, nos casos em que é legalmente admitida, deverá conter ou fazer-se acompanhar por este aviso.

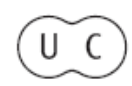




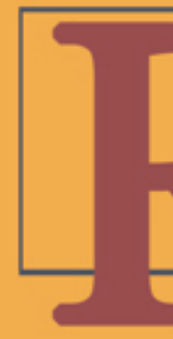

\section{evista de História} da Sociedade e da Cultura

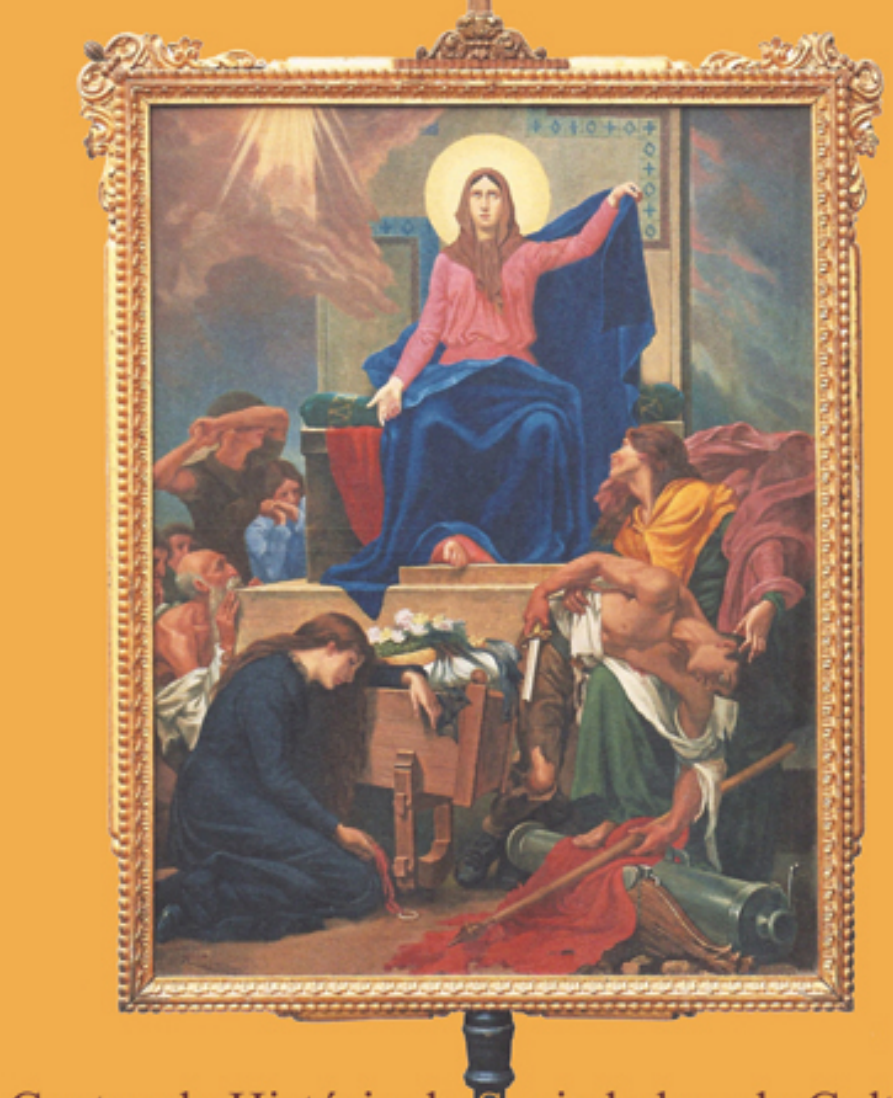

Centro de História da Sociedade e da Cultura Universidade de Coimbra 
os objectivos e as angústias que caracterizam as diferentes épocas, o Autor conclui o seu trabalho sublinhando como essas cerimónias públicas de execução capital fossem muito semelhantes às condenações tecnológicas das prisões dos Estados Unidos. Além disso a história de Lucia Maria Cremoni é um exemplo de reflexão. De várias reflexões. Nas cidades do tempo presente grandes anúncios publicitários de novas instituições querem tranquilizar tensões como esta "Preparada para o parto?", e responde-se oferecendo cursos de preparação e acompanhamento ao parto e pós-parto, aliás da parentalidade. Outras vezes é um perigoso maço de cigarros encontrado no lixo a admoestar "se está grávida: fumar prejudica a saúde do seu filho". Por outro lado, é este ainda o tempo da reprodução de obras de arte humana, de organismos geneticamente modificados, de peças anatómicas intercambiáveis deixadas nas mãos de monstruosas fantasias cirúrgicas, de obsessões e ansiedades comuns e individuais.

\section{Paola Nestola}

paola.nestola@tin.it

Bolseira de Pós-doutoramento da FCT e investigadora colaboradora do Centro de História da Sociedade e da Cultura

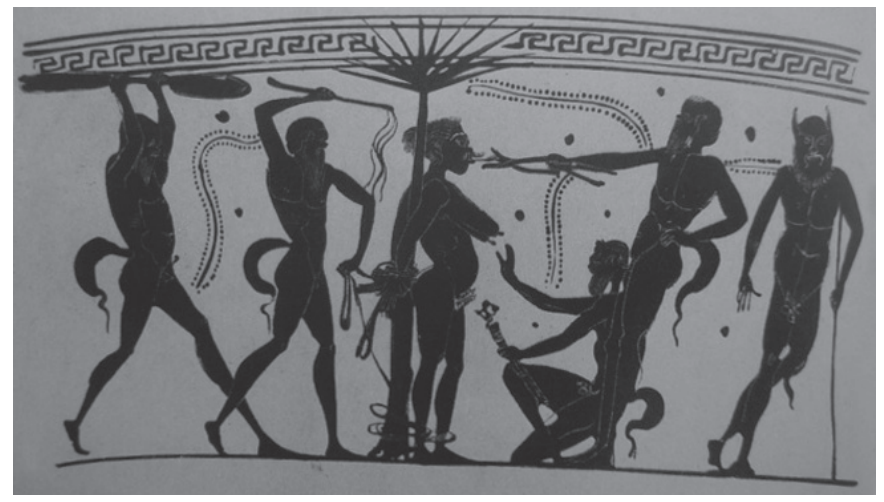

\section{PAIVA, José Pedro - Baluartes da Fé e da Disciplina. O enlace entre a Inquisição e os bispos em Portugal (1536-1750). Coimbra: Imprensa da Universidade de Coimbra, 2011, 480 pgs.}

A criação do Tribunal do Santo Ofício da Inquisição, em 1536, marcou um ponto de viragem na vida religiosa em Portugal. Concedido definitivamente 
pela bula papal Cum ad nil magis, o Tribunal originou uma situação inédita, uma vez que se criava um novo órgão e novos agentes eclesiásticos (os inquisidores), implicando «toda uma reorganização dos equilíbrios de poder, da jurisdição e dos agentes do campo religioso preexistente» (p. 8) no Reino. É este o pano de fundo para o novo livro de José Pedro Paiva, Professor da Faculdade de Letras da Universidade de Coimbra, cujo objectivo foi o de «compor, explicar e pensar os sentidos das relações que se estabeleceram entre a Inquisição e os bispos, no contexto dos desafios suscitados por esta alteração» (p. 8). A obra constitui um estudo rigoroso sobre a relação entre a Inquisição e o episcopado, dois "baluartes da fé e da disciplina" no Portugal Moderno.

A tese de fundo descreve, no essencial, essa relação entre inquisidores e bispos como sendo de cooperação e de sintonia, ainda que nada o fizesse supor, uma vez que, com o surgimento do Santo Ofício, era o episcopado quem mais sofria com a perda de privilégios, de jurisdições e de poder. Com efeito, ao contrário do que se passou na vizinha Espanha e na Península Itálica, em Portugal a Inquisição contou desde o início com o apoio dos antístites. E também desta singularidade portuguesa nos dá conta José Pedro Paiva, num estudo comparado da Inquisição portuguesa com as suas congéneres existentes naqueles dois territórios. $\mathrm{O}$ autor salienta, ainda, a actividade dos inquisidores e dos bispos como disciplinadores da sociedade portuguesa e a sua importância a nível político, enfatizando a preocupação da Coroa na manutenção da boa ordem entre essas duas instâncias. No entanto, também existiram algumas vozes discordantes e alguns momentos de tensão que, igualmente, são referidos e devidamente explicados. Este estudo constitui, pois, um retrato preparado com precisão e com minúcia e que proporciona uma visão clara sobre os laços, os enlaces e os limites existentes na relação entre bispos e inquisidores.

O livro apresenta uma estrutura equilibrada: para além da introdução e da conclusão, comporta cinco capítulos, cada qual abordando uma temática específica e incluindo várias subdivisões, de modo a facilitar a explicação e a demonstração do sentido das relações entre os baluartes da fé e da disciplina. Trata-se de um estudo longo, muito bem escrito e com uma linguagem bastante clara, permitindo uma fácil leitura, bem como uma boa compreensão e apreensão dos conceitos e ideias apresentadas. Todos os temas abordados 
são explicitados com exemplos, com situações alusivas ao respectivo assunto ou mesmo com casos práticos que permitem uma maior clarificação do que está a ser exposto. Durante a investigação, foram analisadas fontes manuscritas e impressas de proveniência variada, desde o Archivo Segreto Vaticano até ao Arquivo da Universidade de Coimbra passando pelo Arquivo Público do Estado do Maranhão, entre muitas outras. Foi também consultada uma vasta bibliografia (portuguesa, italiana, espanhola, francesa, etc). Esse elenco é apresentado no final do livro, sem prejuízo das referências explícitas nas inúmeras (1402) notas de apoio destinadas a abonar, a contrapor ou a justificar muitas das ideias propostas. Neste particular, deve realçar-se que o autor teve o cuidado de chamar a atenção para algumas opiniões com as quais não concorda e para estudos menos consensuais sobre o assunto em apreço. No final da obra, são fornecidos dois utilíssimos instrumentos de trabalho: um "Índice de Nomes de Pessoas e de Instituições" e um "Índice Toponímico".

Em síntese, esta obra apresenta-se como inovadora no panorama historiográfico nacional e internacional, em grande medida como resultado da forma abrangente, integrada e inserida na longa duração com que a investigação foi efectuada. No que diz respeito ao conteúdo específico, passarei agora a levantar um pouco o véu do que é abordado em cada um dos cinco capítulos.

O primeiro capítulo mostra de que forma se efectuou o reajustamento do campo religioso após o estabelecimento da Inquisição e o consequente aparecimento de um novo corpo de agentes eclesiásticos - os inquisidores. À nova instituição foram atribuídas funções de «vigilância da 'pureza da fé', repressão das heresias e disciplinamento de crenças e condutas religiosas, matérias até então sob alçada episcopal» (p. 15). Mas desde o início que o Santo Ofício português procurou expandir o âmbito da sua área de intervenção conseguindo aumentar, progressivamente, o seu poder e competências, até se tornar dominante no plano da definição da ortodoxia religiosa e da perseguição das heresias. Ora, na maioria dos casos, foi o episcopado que se viu lesado nos seus atributos, que agora passavam para o Tribunal da Fé, tal como acontecia no tocante às heresias, cuja competência, antes da criação definitiva da Inquisição, cabia aos auditórios episcopais. Outro aspecto focado respeita aos privilégios de foro dos ministros e oficiais 
do Santo Ofício, isto é, ao facto de serem isentos da jurisdição episcopal. Salienta-se ainda a censura literária desenvolvida pelo Tribunal da Fé, não só para reforçar o facto de se ter imiscuido em mais uma função do episcopado, mas também porque passou a exercer a função censória sobre os textos produzidos pelos próprios bispos, além de interferir nas leituras que lhes eram permitidas. A Inquisição fez de tudo para afirmar e aumentar o seu poder perante o episcopado, procurando um lugar de superioridade e de hegemonia no campo religioso, interferindo nas mais variadas áreas, como por exemplo na confissão, procurando apoderar-se desse poderosa «arma» como fonte de captação de denúncias ou mesmo tentando imiscuir-se em zonas reservadas da esfera episcopal, como a aprovação dos pregadores e dos confessores, ou a pregação, entre outras. De facto, o poder inquisitorial aumentou, impôs-se e enraizou-se na Igreja. Não obstante, e ainda que de forma algo inesperada, o Tribunal da Fé encontrou no episcopado um forte e poderoso aliado, um colaborador e um defensor.

No capítulo seguinte, caracterizam-se as modalidades de colaboração entre a Inquisição e o Episcopado. Salienta-se o facto de os quase três séculos de vida da Inquisição se terem pautado por um clima de harmonia e de profícua colaboração entre aquelas duas grandes referências do campo religioso. Existia uma «convergência tácita de interesses entre as duas instâncias, assente numa comunhão ideológica de fundo, decorrente de uma visão global do mundo, da sociedade, da religião e do tempo, na qual a preservação da ortodoxia da fé católica, tal como definida pela autoridade da Igreja, era um pilar essencial» (p. 140). Era comum o sentimento de que a Inquisição não se criara contra os bispos, mas a favor deles e com eles, até porque a fundação do Tribunal da Fé foi apoiada desde o início por um número significativo de antístites. Havia, assim, um envolvimento e uma colaboração entre as duas partes, que assumiu várias formas e que se manifestou em diferentes áreas, como por exemplo: o desempenho de cargos de topo da Inquisição (sobretudo do lugar de inquisidor-geral) pelos bispos; o fornecimento de informações, de denúncias e de processos ao Tribunal da Fé por parte do episcopado; ou a disponibilização de recursos humanos que permitiram que o Santo Ofício actuasse com eficácia enquanto ainda estabelecia a sua própria rede de pessoal. É certo que existiram desavenças pontuais e arestas a limar, mas, no geral, «bispos e inquisidores estiveram 
enlaçados nesta cruzada para preservar a ortodoxia, mantendo a integridade religiosa de Portugal, pelo que, amparando-se e irmanados, erigiram-se nos baluartes da defesa da fé católica. A história destas relações, até 1745, fez-se mais de laços do que de limites» (p. 188).

Da sintonia ideológica (aliada à colaboração prática já referida) entre episcopado e Inquisição trata o terceiro capítulo. Dá-se uma ideia de como os antístites viam a Inquisição, o lugar que lhe era atribuído na Igreja e na sociedade portuguesa, a função que lhe cabia e quais as suas políticas, e, nesse sentido, demonstra-se como a maioria dos bispos as compartilhava e as defendia. As expressões de apoio dos bispos à acção inquisitorial encontram-se em documentação variada, como missivas, sermões, livros ou até na sua activa participação nos autos-da-fé. Mas uma via bem mais credível para averiguar a convergência ideológica entre os "bispos pastores" e os "inquisidores vigias" passará por perceber a posição assumida pelo episcopado em fases críticas da vida da Inquisição. Assim, podemos dizer que, até ao final do século XVII, sempre que a independência ou a capacidade de acção do Santo Ofício foram ameaçadas ou postas em causa, os bispos uniram-se e defenderam o estatuto institucional, os privilégios e os modos de actuação do Tribunal da Fé. José Pedro Paiva escolheu os seguintes quatro momentos para demonstrar esta postura do episcopado: «o estabelecimento da Inquisição e as dificuldades levantadas à sua autonomia de actuação; o perdão geral concedido aos cristãos-novos em 1604-1605; as tentativas de reforma do Tribunal no reinado de D. Filipe IV, que culminaram com a publicação, em 1627, de um édito da graça especial para os cristãos-novos; e a suspensão da actividade da Inquisição imposta pelo papado entre 1674 e 1681» (p. 213).

O quarto capítulo conduz a análise para lá do plano religioso, de maneira a enquadrar este na sua relação com a política. De facto, eram profundas as articulações entre estes dois aspectos da vida da sociedade. Ao estudar a actuação da Inquisição e do episcopado, e pensando sobretudo na forte acção que ambos tiveram no disciplinamento da população, não podemos deixar de ver aquelas duas instâncias como fortes aliadas da Coroa, transmitindo à população noções de hierarquia, de ordem e de obediência que configuravam a base de uma forte coesão social, facilitando e promovendo assim a afirmação do poder político. O disciplinamento dos crentes enraizava a 
obediência dos vassalos e essa era uma das razões principais para que a aliança e a cooperação entre estas entidades eclesiásticas, que tinham competências nestes domínios, fosse de todo o interesse para a monarquia. Este enlace permitia uma divisão do trabalho de disciplinamento e vigilância do comportamento das populações, tendo-se construído uma cooperação sólida, caracterizada por uma profícua complementaridade entre o Santo Ofício e o episcopado. Criou-se um sistema que repartia entre estes dois poderes o esforço de normalização e de vigilância dos comportamentos, das crenças religiosas e do doutrinamento das populações, ou seja: «bispos e inquisidores vigiaram espaços diferenciados; concentraram a actuação sobre estratos sociais da população distintos; puniram crenças religiosas e comportamentos de diferente tipo; e utilizaram métodos de actuação desiguais» (p. 267). Assim, podemos dizer que os bispos desempenharam o papel de pastores, sendo os principais responsáveis pela instrução, pelo enquadramento sacramental e pela vigilância dos comportamentos morais e da prática religiosa dos fiéis. Por sua vez, os inquisidores actuaram como vigias, concentrando a atenção na defesa da ortodoxia através da severa e pública repressão das heresias (p. 301). Na verdade, a Igreja, ao transmitir aos seus fiéis uma doutrina para acreditarem e obedecerem, contribuiu para o aprofundamento do processo de subordinação dos vassalos à Coroa. É de valorizar a importância destes dois baluartes da fé para a construção do Portugal Moderno, uma vez que a Coroa soube servir-se deles para moldar a sociedade - ao mesmo tempo que se disciplinava o crente, disciplinava-se também o vassalo...

O quinto e último capítulo principia com a apresentação do estudo comparado da relação entre bispos e Inquisição nos três espaços que vão sendo referenciados ao longo de toda a obra: Portugal, Espanha e Península Itália, destacando-se neste particular a originalidade da situação portuguesa. De seguida, estudam-se algumas excepções à regra do que foi a relação existente entre o Santo Ofício e os bispos em Portugal, isto é, os momentos em que se verificaram situações de discórdia e polémicas, motivadas sobretudo pelas seguintes razões: a jurisdição em relação a delitos de foro misto; os lugares a ocupar nos rituais e nas cerimónias, sobretudo públicas; o pagamento de pensões à Inquisição sobre rendas episcopais; e a aceitação dos procuradores nomeados pelos bispos para os representarem no desem- 
bargo e na votação dos processos inquisitoriais. De referir que, na maioria dos casos, o Tribunal da Fé acabou por fazer vingar a sua vontade, consolidando assim uma posição de superioridade na definição do seu estatuto e das suas políticas. Analisam-se ainda, neste derradeiro capítulo, as atitudes de alguns bispos que não seguiram a opinião da maioria, criando para si percursos alternativos sem com isso assumirem posições de fractura ou de oposição aberta ao Santo Ofício. Neste ponto, identificam-se quatro perfis distintos: i) os defensores da jurisdição e da autoridade que possuíam antes da criação da Inquisição; ii) os bispos que, saídos das fileiras da Inquisição e governando dioceses periféricas, perpetuaram uma actuação autónoma no julgamento de heresias; iii) os apologistas de vias mais suaves de vigilância da ortodoxia e de instauração da disciplina católica; iv) e os protagonistas de percursos oscilantes e com um padrão de actuação difícil de definir, porque marcado por alguma ambiguidade. Por fim, apresenta-se a reconstituição dos dois únicos episódios que colocaram em confronto grupos de bispos, por um lado, e a Inquisição portuguesa, por outro, «mostrando como, nos meados do século XVIII, os baluartes da fé e da disciplina perdiam consonância ideológica» (p. 418). Assim se anunciavam já os novos tempos; como explica o autor, «na relação entre bispos e inquisidores iam medrando mais limites do que laços» (p. 418).

Apresentado, nas suas linhas gerais, este excelente trabalho (mais um com a chancela da Imprensa da Universidade de Coimbra) sobre o relacionamento entre a Inquisição e os bispos em Portugal no período compreendido entre 1536 e 1750, resta-me referir que, dentro dos estudos disponíveis sobre o tema, o novo livro de José Pedro Paiva propõe uma abordagem inovadora e suscita questões e problematizações que farão dele uma obra de referência no quadro da historiografia da Época Moderna, das estruturas eclesiásticas e, muito em especial, da Inquisição.

\section{Carla Rosa}

Aluna do $1^{\circ}$ ciclo em História da Faculdade de Letras da Universidade de Coimbra crmargarida@gmail.com 